\title{
La extensión universitaria crítica ante la avanzada neoliberal
}

\author{
The Critical University Extension in the Face of the \\ Neoliberal Advance
}

\author{
Andrés Ariel Robles Barrantes \\ Universidad Nacional \\ Heredia, Costa Rica \\ andres.robles.barrantes@una.cr
}

Recibido: 01/06/2020 Aceptado: 31/08/2020

\begin{abstract}
Resumen. El presente ensayo representa una mirada de la extensión desde su perspectiva crítica y constructora de un diálogo de saberes donde es posible reivindicar la universidad pública ante el ataque y la avanzada del modelo económico neoliberal en Latinoamérica. La extensión universitaria entendida como un vínculo dialógico y dialéctico entre la universidad y las comunidades, para de esta forma reivindicar desde una lectura histórica cuáles son las bases y los fines de la extensión y qué repercusiones posee en la construcción de conocimientos que trascienden los espacios académicos y tradicionalmente científicos, incluyendo los saberes más populares y ancestrales. La universidad como una inversión social legitimada en las comunidades y regiones, apoyada por los sectores de mayor limitación económica y reconocida por los diferentes actores sociales a partir de sus esfuerzos extensionistas en diversos rincones de Latinoamérica.
\end{abstract}

Palabras clave: extensión, enfoque crítico, neoliberal, universidad.

\begin{abstract}
This essay represents a look at the university extension from a critical perspective. It aims to understand the economic challenges introduced by neoliberalism into the Latin-American universities. The extension in universities symbolizes a significant action that covers a dialectic bond between the communities and educational institutions. In this academic paper, the university characterizes a social investment validated by its work in the communities and regions, especially when there has been exclusion and limitation. Correspondingly, it remarks, from a historical point of view, the basis, goals, and effects of the university extension in Latin-American countries.
\end{abstract}

Keywords: critical analysis, extension, neoliberalism, university. 
Revista Universidad en DiÁlogo • Vol. 10, N. 2, Julio-Diciembre, 2020 • 167-179

ISSN 2215-2849 • EISSN: 2215-4752

URL: https://www.revistas.una.ac.cr/index.php/dialogo/index Correo electrónico: universidadendialogo@una.ac.cr

DOI: https://doi.org/10.15359/udre.10-2.9

\section{Conceptualización de la extensión universitaria}

La extensión universitaria representa una de las labores fundamentales que realizan las casas de enseñanza superior en conjunto con la investigación y la docencia. Su conceptualización puede ser abordada a partir de diferentes planteamientos epistemológicos, sin embargo, para efectos de este ensayo académico, debe ser comprendida desde su contextualización en un enfoque latinoamericanista. Aunque claramente es posible identificar diferentes textos que hacen referencia a la extensión y sus orígenes. Por ejemplo, desde 1898, el catedrático español Adolfo González Posada acuñó el término, también se pueden identificar las actividades relacionadas a la difusión cultural y la divulgación científica que fueron dirigidas a los sectores más empobrecidos de las sociedades desde el nacimiento de las universidades populares en Francia y Bélgica, los Intercambios de Verano en Inglaterra y las Misiones Pedagógicas en España, que constituyeron los primeros pasos de procesos de extensión universitaria (Núñez, Álvarez y Martínez, 2017). Es posible incluso encontrar planteamientos previos en Gran Bretaña durante el año 1790, con programas educativos de formación para personas adultas o Estados Unidos en 1860-62 en cuanto al trabajo con campesinos en centros de enseñanza (Chaves, Lara y Villalobos, 2017). Es decir, dilucidar el origen del concepto podría partir de muchas aristas y ejemplos diferentes. Sin embargo, este desarrollo conceptual se vería altamente influenciado primordialmente en Latinoamérica, aunque tuvo también sus repercusiones en el resto del mundo, por la Reforma de Córdoba dada en Argentina de 1918. La misma llegaría a dar una mirada más profunda de la labor universitaria y su responsabilidad política, económica y social, mirada que arrojaría señales incluso en la labor extensionista de los centros de educación superior.

Sin duda, tienen fundamental importancia e implicaciones no solo para Latinoamérica, sino también para otras regiones, los hechos dados en la Reforma de Córdoba. Existían incluso antes de este movimiento algunas iniciativas de personas académicas especialmente influenciadas por pensamientos anarquistas y socialistas que desarrollaron esfuerzos por acercar actividades universitarias a los sectores más populares de nuestra sociedad (Núñez, Álvarez y Martínez, 2017). Pero es a partir de lo ocurrido en Argentina que despiertan y toman fuerza nuevas percepciones e ideas de lo que se comprende como universidad y de esta forma también lo que se visualiza como extensión universitaria. Tal como lo plantea Tünnermann (1998), "el Movimiento de Córdoba, que se inició en junio de 1918, fue la primera confrontación entre una sociedad que comenzaba a experimentar cambios de su composición interna 
URL: https://www.revistas.una.ac.cr/index.php/dialogo/index CORREO ELECTRÓNICO: universidadendialogo@una.ac.cr DOI: https://doi.org/10.15359/udre.10-2.9

y una Universidad enquistada en esquemas obsoletos" (p. 104). Impulsando cambios que darían una mirada de cuáles deberían ser las funciones de las universidades y a quiénes deben dirigirse. En cuanto a la extensión universitaria, la reforma contempló sus aportes en el ámbito de la misión social que deben desarrollar las casas de enseñanza superior, sobre esto Acevedo (2011) explica sus alcances:

...para que su función social fuese mucho más allá de la simple enseñanza de las aulas de clase. La educación universitaria debía involucrarse en la investigación y la solución de los problemas de la sociedad y de las naciones. Lo que hoy se llama la extensión universitaria. (p. 9)

Dando de esta forma un impulso al entendimiento de la universidad como un espacio que tiene la responsabilidad de vincularse, responder y trabajar en conjunto con la sociedad para superar sus dificultades. Este sería un rompimiento trascendental con la forma en que se gestionaba y entendía la universidad en esa época, donde la educación superior era manejada por élites económicas y la oligarquía, además de preservar una vinculación importante con la Iglesia católica.

Desde este planteamiento inicial, es posible identificar diferentes corrientes de pensamiento que con el pasar de los años han ido aportando en lo que se entiende o no como procesos de extensión de las universidades. Se ha ido construyendo un campo de desempeño académico sumamente diverso en el que se pueden contemplar diversas prácticas. Tommasino y Cano (2016) comentan sobre esta disyuntiva planteando que "la extensión se construye como un campo del quehacer universitario sumamente heterogéneo" (p. 8). Es decir, un espacio conceptual donde es posible contemplar diferentes formas de entender, gestionar y aplicar procesos de extensión universitaria. Dentro de estos múltiples fines de la extensión universitaria es posible contemplar su desarrollo desde una perspectiva crítica, estrechamente relacionada con procesos de formación profesional desde una vinculación activa con la realidad de las comunidades.

\section{La extensión desde una perspectiva crítica}

Plantear la extensión desde un enfoque crítico implica su entendimiento y fundamento desde diferentes influencias conceptuales que provienen de corrientes filosóficas, ideológicas y políticas. En ese sentido, Tommasino y Cano (2016) indican que la extensión crítica "articula elementos de la tradición pedagógica del movimiento de la educación popular latinoamericana (en su 
Revista Universidad en Diálogo • Vol. 10, N. 2 2, Julio-Diciembre, 2020 • 167-179

ISSN 2215-2849 • EISSN: 2215-4752

URL: https://www.revistas.una.ac.cr/index.php/dialogo/index Correo electrónico: universidadendialogo@una.ac.cr

DOI: https://doi.org/10.15359/udre.10-2.9

vertiente freiriana) y de la investigación-acción-participación (en su tradición falsbordiana)" (p. 12). Bajo este entendido, es necesario fundamentar tanto la influencia desde la educación popular y la pedagogía crítica como la investigación-acción participativa para poder comprender los alcances de la extensión desde este fundamento y sus implicaciones.

En cuanto a la educación popular y la pedagogía crítica, es necesario remarcar su desarrollo desde un origen y construcción latinoamericanista. Esto ante los múltiples esfuerzos que se han efectuado en diferentes países donde educadores populares desempeñan diferentes iniciativas por alcanzar la emancipación de los sectores más empobrecidos de la región desde la educación como instrumento liberador y fuente de movilidad social.

La construcción de esta corriente pedagógica reside en las reflexiones, las investigaciones y los aportes prácticos del brasileño Paulo Freire. Sobre la educación como práctica para la libertad, el mismo Freire (1987) menciona que "por ser educación, habría de ser valiente, ofreciendo al pueblo la reflexión sobre sí mismo, sobre su tiempo, sobre sus responsabilidades, sobre su papel en la nueva cultura de la época" (p. 51). Esta forma de entender la educación trasciende las lógicas sistemáticas u oficialistas donde se plantean los procesos educativos como espacios de formación meramente en función del mercado. Se plantea, muy por lo contrario, la necesidad de entender lo pedagógico desde el entendimiento, la incidencia y la transformación de las condiciones que viven las personas.

Un segundo componente en la extensión crítica radica en la investigaciónacción desde su entendimiento más participativo. Nuevamente, es notable en esta mirada una fuerte influencia del pensamiento latinoamericano. Se destaca en la construcción del concepto de la investigación-acción participativa (IAP) el desarrollo brindado por el colombiano Orlando Fals Borda. Este método investigativo sustentado por la sociología, pero con fuertes repercusiones en la educación, brindó una nueva comprensión de los fenómenos sociales y la posibilidad de incidir en ellos. Sobre este concepto, Calderón y López (2013) mencionan que:

Esta nueva forma de investigar es una vivencia que transforma las relaciones entre investigador e investigado, entre estudiante y maestro, superando por completo tales dicotomías, poniendo como prioridad la producción de conocimiento a partir del diálogo con quienes construyen la realidad, que se entiende como propia de los sujetos que participan de la construcción de conocimiento social. (p. 3) 
URL: https://www.revistas.una.ac.cr/index.php/dialogo/index CORREO ELECTRÓNICO: universidadendialogo@una.ac.cr DOI: https://doi.org/10.15359/udre.10-2.9

En otras palabras, este método resulta un enlace entre la teoría y la práctica en que el conocimiento surge de un diálogo colectivo. No es una imposición, ni tampoco un lineamiento desde el pedestal académico, es la construcción del conocimiento desde la apertura a la diversidad y la capacidad de que quienes participen en el proceso investigativo puedan contribuir para transformar diferentes realidades.

A partir de estos postulados es posible entender los orígenes de la extensión crítica como una forma de vincular la universidad con los sentidos más sociales y humanos, un proceso en búsqueda de trabajar en conjunto con diferentes actores sociales para el mejoramiento de sus condiciones, muchas veces penetradas por la injusticia y la desigualdad. Nuevamente, Tommasino y Cano (2016) señalan en esta línea que "la extensión concebida como un proceso crítico y dialógico se propone, en cambio, trascender la formación exclusivamente técnica que genera la universidad "fábrica de profesionales'" (p. 15). Esto conlleva entender la extensión como un medio que va más allá de las dinámicas meramente técnicas que se dan en la enseñanza superior, las mismas que cada vez aparecen con mayor contundencia en una educación basada en la formación tecnócrata. Se constituye de esta forma en un medio que para comprender la extensión se sustenta en un origen altamente latinoamericanista, no solamente en su concepto, sino también en sus implicaciones prácticas. Esto es evidente al retomar las acciones en búsqueda de un bien común, una transformación social y una vinculación comunitaria con los sectores populares. Un accionar que, sin duda, contiene un carácter más político frente a los efectos de los sistemas imperantes.

La extensión crítica puede constituir un proceso de sensibilización profesional de las personas estudiantes que se encuentran cursando sus carreras en las universidades. Es decir, la extensión "se vincula con la formación de los universitarios y la posibilidad de establecer procesos integrales que rompan con la formación profesionalista alejada de un criterio de compromiso social de los graduados universitarios" (Tommasino y Cano, 2016, p. 15). Constituye la oportunidad de dar a las personas formadas en las universidades la posibilidad de trabajar en su compromiso con la sociedad, especialmente a las personas que más lo necesitan.

Finalmente, es necesario remarcar que la extensión constituye una práctica desarrollada desde una institución educativa y por ende es innegable la vinculación que existe entre la extensión y la educación. A partir de ahí, es importante recalcar que la educación es un acto político. Freire (1985) explica que: 
La educación, sea en la universidad, la escuela secundaria, la primaria o en la alfabetización de adultos, es un acto político. ¿Por qué? Porque la naturaleza misma de la educación tiene las cualidades inherentes para ser política, así como la política posee aspectos educativos. (p. 184)

Desde esta argumentación, es posible indicar que todo lo que implique una relación con un proceso educativo tiene una función política y en este aspecto la extensión universitaria forma parte también de ese paradigma. Se puede agregar sobre la extensión crítica que "en su dimensión política, esta perspectiva de la extensión se propone contribuir a los procesos de organización y autonomía de los sectores populares subalternos intentando aportar a la generación de procesos de poder popular" (Tommasino y Cano, 2016, p. 15). Es por medio de esta perspectiva que la extensión universitaria crítica surge como una alternativa de transformación social, altamente dialógica, basada en un intercambio de saberes, pero principalmente con un claro accionar político.

\section{La extensión universitaria crítica como diálogo de legitimación social}

En el escenario actual (año 2020) que enfrenta la universidad es cada día más necesaria su legitimación ante la sociedad. La educación superior pública a lo largo de Latinoamérica se encuentra enfrentando un sinnúmero de ataques emitidos, en la mayoría de los casos por el poder económico y la necesidad de implementar las regulaciones del sistema económico neoliberal. Ante esto, las instituciones son constantemente cuestionadas, al ser fuentes del presupuesto público.Aquí, es evidente el ataque fundamentado desde un discurso político que argumenta la educación superior pública como un gasto de los Estados y no como una inversión social, y de esta manera justifica su privatización. Se vuelve entonces fundamental que la labor de las universidades sea apoyada y defendida por los diferentes actores sociales que entienden y confian en su labor. Es un proceso en el que la universidad construye su legitimidad a partir de la confianza de los otros actores o las instituciones con las que interactúa. Villanueva (2011) indica sobre la construcción de esta relación que "la confianza en una institución de educación superior, como en sus evaluadores, tiene una función: evitar el riesgo de las fechorías, las trampas, los engaños y la irresponsabilidad en la enseñanza y formación de profesionales" (p. 63). En otras palabras, la confianza que se constituye en la credibilidad con la que cuenta una institución para poder realizar sus gestiones con tranquilidad y sin amenazas.

Es posible entender que son las funciones de las universidades las que verdaderamente la legitiman en su contexto. Desde esta perspectiva, Boaventura de Sousa (2006) indica que "son cinco las áreas de acción en este campo: acceso, extensión, investigación-acción, ecología de saberes, universidad y escuela pública” (p. 60). 
URL: https://www.revistas.una.ac.cr/index.php/dialogo/index CORREO ELECTRÓNICO: universidadendialogo@una.ac.cr DOI: https://doi.org/10.15359/udre.10-2.9

Este planteamiento resalta, entre otras actividades, la labor de la extensión como un medio de legitimación social de las universidades. Esto a partir de su labor en un diálogo constante con diversos actores que se involucran en la transformación de las condiciones sociales que ameriten cambios. Un proceso que requiere un intercambio de saberes en el que contribuyen el conocimiento científico y los conocimientos populares y ancestrales, a un mismo nivel, ninguno por encima de otro, todos en un diálogo dialéctico y por lo tanto también transformador. Para esto "las actividades de extensión deben tener como objetivo prioritario...el apoyo solidario para la resolución de los problemas de exclusión y la discriminación sociales, de tal modo que se dé la voz a los grupos excluidos y discriminados" (Boaventura, 2006, p. 67). Se concluye nuevamente en el componente político que contiene la extensión universitaria y su labor e influencia claramente antagonista de los intereses del modelo económico neoliberal.

Finalmente, sobre este apartado, es necesario remarcar que existen intereses de grupos de poder por confundir labores extensionistas con actividades lucrativas. Esta labor surge como fundamento para justificar la generación de recursos extras, argumento estrechamente relacionado con el discurso de la reducción del financiamiento de las universidades públicas y encaminarse a la privatización de las casas de enseñanza superior. Nuevamente, Boaventura de Sousa (2006) comparte sobre la extensión que "es necesario evitar que sea orientada hacia actividades rentables con la finalidad de recaudar recursos extrapresupuestarios. En este caso estaremos frente a una privatización discreta (o no tan discreta) de la universidad pública" (pp. 66-67).

Es evidente que la intencionalidad detrás de generar servicios universitarios bajo los parámetros de lucro y rentabilidad responde a los intereses privatizadores que funcionan en respuesta de los grupos de poder económico y las exigencias del mercado capitalista. Teniendo clara esta distinción, es por eso oportuno que las universidades apuesten por procesos reivindicativos, emancipadores y liberadores que van al encuentro de los sectores sociales más excluidos sin costo alguno. Logrando cada vez más afianzar su legitimidad ante la sociedad. Evidentemente, al ser instituciones públicas ya están siendo financiadas por esos mismos sectores a los que se acercan para construir alternativas transformadoras de sus necesidades más apremiantes, y por tanto la legitimidad alcanzada es su única garantía ante las amenazas políticas y económicas.

\section{La avanzada neoliberal y la universidad en riesgo}

La lógica del sistema económico imperante tiene el fin primordial de que toda actividad sea utilizada como una mercancía en función de la generación de 
Revista Universidad en DiÁlogo • Vol. 10, N. 2, Julio-Diciembre, 2020 • 167-179

ISSN 2215-2849 • EISSN: 2215-4752

URL: https://www.revistas.una.ac.cr/index.php/dialogo/index CORREO ELECTRÓNICO: universidadendialogo@una.ac.cr

DOI: https://doi.org/10.15359/udre.10-2.9

réditos económicos. La misma amenaza a todas luces las funciones de las universidades públicas, cuyos intereses responden a otras dinámicas. Robles Barrantes (2020) remarca que "la universidad latinoamericana se encuentra en una realidad compleja donde un sistema económico ha impuesto las reglas en las que debe regirse" (p. 4). Un sistema económico que busca la reducción de la influencia del Estado en diversas actividades, y que estas sean más bien reguladas por las lógicas del mercado, sin intervención del Estado como medio de distribución u organización a través de la institucionalidad pública. La imposición del modelo económico neoliberal que ha tenido como característica elemental la privatización de servicios fundamentada en un discurso de mejora en la productividad y eficiencia de esos servicios.

La educación pública en general, incluyendo la educación superior, no escapa de los alcances de este modelo, siendo vista como uno de esos servicios que pueden ser mercantiles y productivos para la generación y acumulación de riqueza característica en el neoliberalismo. Sobre esto, Boaventura de Sousa (2006) establece que "este traspaso del límite en la presión productivista desvirtúa la universidad, llegando inclusive a vaciar sus objetivos más inmediatos de cualquier preocupación humanista o cultural" (p. 30). Se enmarca entonces un panorama donde la educación universitaria pública debe dejar de centrarse en las personas para enfocarse en el mercado. Fenómeno que se da de forma generalizada en todo el sistema educativo, donde a partir de su debilitamiento se abre camino a "procesos de mercantilización de la educación donde su rol responde a un comportamiento de adquisición y consumo, en donde incluso en muchas regiones la educación se vende y compra como cualquier otro servicio" (Robles, 2020, p. 5). Se encuentra dentro de este panorama la universidad pública en una encrucijada que la coloca en una situación de riesgo.

Los resultados de la implementación de estas imposiciones económicas pueden ser lapidarios para las funciones que desarrollan las instituciones desde la educación superior pública. Los efectos de un cambio de paradigma, donde las funciones universitarias son transformadas, por ejemplo, "el caso de la educación permanente que se ha reducido a la educación para el mercado permanente" (Boaventura de Sousa, 2006, p. 30). Sobre esta situación que se enfrenta, se vuelve de suma importancia prestar atención ante una serie de aspectos de gran relevancia, entendiendo que, tal como lo plantea Boaventura de Sousa (2006), "con la transformación de la universidad en un servicio al que se tiene acceso, no por vía de la ciudadanía sino por vía del consumo, y por lo tanto mediante el pago, el derecho a la educación sufrió una erosión radical”. Estos cambios ponen al derecho a la educación ante un 
URL: https://www.revistas.una.ac.cr/index.php/dialogo/index CORREO ELECTRÓNICO: universidadendialogo@una.ac.cr DOI: https://doi.org/10.15359/udre.10-2.9

condicionamiento económico, que plantea que solo quienes pueden pagarlo tendrán acceso. Además, actividades sustantivas de las universidades, como la investigación y la extensión, corren riesgo de erosión, al ser vistas como no fundamentales desde una lógica económica, donde se plantea que lo que no sea productivo no debe requerir esfuerzos e inversiones significativas. Al igual que el entendimiento de las universidades como instituciones que se autogestionan sin el apoyo o la inversión del Estado.

Aquí, se vuelve prioritaria la reflexión sobre el funcionamiento de las universidades públicas, su compromiso y la forma en que pueden enfrentar los desafíos que se encuentran en su futuro inmediato. Desde ahí, también el rol que desempeña la extensión universitaria y su capacidad por combatir los ataques a los que se encuentra sujeta esta acción sustantiva. Reivindicar el concepto de universidad debe partir de entender que "en el siglo XXI sólo habrá universidad cuando haya formación de grado y de postgrado, investigación y extensión. Sin cualquiera de estas habrá enseñanza superior pero no habrá universidad" (p. 59). En este sentido, la labor de la extensión debe entenderse como un elemento trascendental en el funcionamiento de la universidad y su rol en un contexto social, retomando y trayendo a la vigencia la idea de Universidad Latinoamericana defendida desde la Reforma de Córdoba de 1918. Avocando también a que la extensión constituye un instrumento universitario de incidencia con carácter político, que posee gran repercusión social e intenta contrarrestar los efectos del modelo económico imperante, al ser un sistema altamente excluyente y desigual.

\section{La extensión como fuente de emancipación y liberación}

¿Por qué la extensión se ve afectada por los intereses económicos? ¿Representa verdaderamente un gasto? ¿Podría ser la extensión universitaria una amenaza para los intereses neoliberales? Son tal vez algunas de las interrogantes que surgen después de analizar la situación que se ha expuesto a lo largo de este ensayo académico. Cuestionamientos que invitan a reflexionar y problematizar sobre las repercusiones de los procesos extensionistas dentro de los contextos sociales en los que se desarrollan. Entender la incidencia de las acciones sociales implementadas desde la extensión universitaria puede llevar en un primer paso a comprender que esta labor, como se ha dicho en otras ocasiones, no representa un gasto, sino más bien una responsabilidad de la universidad. Comprender que el ataque que recibe desde los modelos económicos imperantes podría estar relacionado con el componente político altamente emancipador y transformador que representa un aspecto medular de la extensión. 
Revista Universidad en DiÁlogo • Vol. 10, N. 2, Julio-Diciembre, 2020 • 167-179

ISSN 2215-2849 • EISSN: 2215-4752

URL: https://www.revistas.una.ac.cr/index.php/dialogo/index Correo electrónico: universidadendialogo@una.ac.cr

DOI: https://doi.org/10.15359/udre.10-2.9

La extensión universitaria tiene sin duda una capacidad emancipadora y liberadora. Primeramente, es necesario comprender que la extensión universitaria "constituye a sí misma un espacio de conflicto" (Cano, 2015, p. 23). Tanto por los planteamientos antes mencionados como por el desarrollo de este concepto desde diferentes epistemologías. Sin embargo, desde la extensión crítica, es importante contemplar incluso el rol de la persona extensionista. Cano (2015) lo describe diciendo que:

En el modelo de la extensión crítica, el extensionista es un intelectual participante de una relación de saber-poder, consciente de las tensiones y contradicciones histórico-sociales que sobre determinan dicha relación, así como de la imposibilidad de asumir una posición neutral respecto a las mismas. (p. 38)

Se determina de esta forma que la persona encargada de la labor extensionista debe comprender las dinámicas en las que se desenvuelve y posicionarse como un intelectual que funciona de manera orgánica. Un intelectual orgánico, en palabras de Gramsci (1967), quien acuñó el concepto, “debe ser organizador de masas" (p. 21). Una persona que comprendo con claridad que no es neutral y que al igual que en el proceso extensionista tiene una labor política.

La extensión al contar con una vocación claramente pedagógica tiene además un rol emancipador desde donde es posible la construcción de transformaciones construidas a partir del trabajo conjunto con los actores sociales que han sido históricamente excluidos. Labor que al mismo tiempo retroalimenta y de alguna forma también emancipa el conocimiento y la labor universitaria. Cano (2015) recalca que esto se desarrolla "procurando la creación de conocimiento sobre el potencial político, académico y pedagógico de la extensión en la transformación de la propia institución universitaria en diálogo con los sujetos populares que instituye como interlocutores" (p. 46). Se vuelve necesario remarcar la labor dialógica como un instrumento recíproco, no es posible que exista emancipación a partir de la imposición unilateral de un discurso desde el pedestal académico.

Por el contrario, lo siguiente es fundamental: "La revitalización y resignificación del compromiso social de la universidad necesita de movimientos que desde lo social sean capaces de proyectar alternativas de sociedad desde las cuales reclamar, interpelar y defender el compromiso de la universidad" (Cano, 2015 , p. 23). Concluyendo en que la universidad se alimenta por medio de la extensión y se legitima a partir de los aportes de todos aquellos movimientos y actores que de forma recíproca contribuyen. 
URL: https://www.revistas.una.ac.cr/index.php/dialogo/index CORREO ELECTRÓNICO: universidadendialogo@una.ac.cr DOI: https://doi.org/10.15359/udre.10-2.9

Se vuelve esencial comprender que, desde esta percepción, la extensión universitaria asume un rol transformador. Un proceso que va más allá de cualquier dinámica basada en la venta de un servicio o el comprender la educación superior como una actividad mercantil. La universidad entendida como un elemento fundamental enmarañado en la identidad social, como una institución que antepone las necesidades colectivas como su fundamento para desarrollar sus labores sustantivas.

\section{Conclusiones generales}

- La extensión universitaria parte de una conceptualización de larga data, en la que no se puede negar sus primeros aportes desde las universidades europeas, que impulsaron a partir de diferentes esfuerzos la vinculación entre las instituciones de educación superior y las necesidades de las comunidades u otros actores sociales. Sin embargo, a partir de la experiencia latinoamericana es posible constituir un concepto más acorde con la realidad regional, que represente los mayores sentires, las experiencias que surgen como una herencia histórica, al igual que un aporte a la construcción del conocimiento decolonial.

- La extensión crítica representa un abordaje con una claridad evidente de las circunstancias que se enfrentan desde las acciones sociales desarrolladas desde las universidades. Surge como una alternativa que comprende el rol político de las universidades y, por medio de estas, las diferentes labores sustantivas que representan sus funciones primordiales. Una extensión que va en búsqueda de los sectores más olvidados, excluidos y empobrecidos por los sistemas económicos, para a partir del trabajo conjunto con los mismos poder construir alternativas que logren la transformación de sus condiciones y dificultades más penetrantes.

- La extensión universitaria representa un medio de legitimación de la universidad y su hegemonía social, política y cultural. Es por medio de acciones de incidencia de este campo que las instituciones de educación superior pueden entablar un diálogo constante con otros actores sociales. Desarrollando lazos que estarán vigentes para preservar y defender la idea de una institución abiertamente popular y comprometida con los diferentes actores sociales que requieran de sus aportes. 
- Existen una serie de amenazas desde los fundamentos capitalistas y las tendencias neoliberales que aún se encuentran con vigencia en diferentes regiones latinoamericanas que atentan contra el modelo de universidad pública, inclusiva, popular y comprometida con los sectores sociales. En ese escenario complejo, le corresponde a la universidad impulsar esfuerzos para mantenerse con vigencia y defender el derecho a la educación como una necesidad humana que no puede tener precio, ni estar al servicio de las lógicas impuestas por el mercado. Dentro de esta divergencia de posiciones, la extensión universitaria representa un espacio de amenaza constante, un campo de batalla que se desenvuelve tanto en lo ideológico como en lo político.

- Finalmente, se vuelve prioritario remarcar que la extensión universitaria se encuentra estrechamente relacionada con la labor pedagógica. Ambas cuentan con componentes políticos con total capacidad para incidir de manera significativa en las dinámicas sociales. Su vocación en este sentido debe partir de principios que se centran en la emancipación, reivindicación y transformación. Esta función parte de contar con la claridad para entender que la universidad como un actor político incide en su entorno y genera cambios en favor de los colectivos que enfrentan mayor desigualdad.

\section{Referencias bibliográficas}

Acevedo, A. (2011). A cien años de la Reforma de Córdoba, 1918-2018 la época, los acontecimientos, el legado. Revista Historia y Espacio, 7 (36). https://dialnet.unirioja.es/servlet/articulo?codigo $=3797042$

Boaventura, S. (2006). Universidad popular del siglo XXI. Lima: Fondo Editorial de la Facultad de Ciencias Sociales.

Cano, J. (2015). La extensión universitaria en la transformación de la universidad latinoamericana del siglo XXI: Disputas y desafios. http:// biblioteca.clacso.edu.ar/clacso/becas/20141202093928/ensayo_cano_ premio_pedro_krotsch.pdf

Calderón, J. y López, D. (2013). Orlando Fals Borda y la investigación acción participativa: aportes en el proceso de formación para la transformación. Buenos Aires: Centro Cultural de la Cooperación. 
Chaves, S., Lara, C. y Villalobos, A. (2017). Desarrollo de la extensión en las universidades estatales costarricenses. Influencias, modelos y desafíos actuales. Revista $+E$, 7(7),122-131. doi: https://doi.org/10.14409/ extension.v0i7.7057

Freire, P. (1985). La naturaleza política de la educación: cultura, poder y liberación. Barcelona: Centro de Publicaciones del Ministerio de Educación y Ciencia y Ediciones Paidós Ibérica.

Freire, P. (1987). La educación como práctica de la libertad. Distrito Federal, México: Andrómeda.

Gramsci, A. (1967). La formación de los intelectuales. Distrito Federal, México: Editorial Grijalbo.

Núñez, A., Álvarez, B. y Martínez, C. (2017). La extensión universitaria y su relación con la formación inicial de las carreras pedagógicas en Cuba. Revista Actualidades Investigativas en Educación, 17 (3), 1-21. doi: https://doi.org/10.15517/aie.v17i3.30280

Robles, A. (2020). La evaluación anacrónica desde la docencia universitaria. Revista Educación, 44 (1). doi: https://doi.org/10.15517/revedu. v44i1.36367

Tommasino, H., \& Cano, A. (2016). Modelos de extensión universitaria en las universidades latinoamericanas en el siglo XXI: Tendencias y controversias. Revista Universidades, 67, 7-24. Recuperado de https:// accionsocial.ucr.ac.cr/sites/default/files/adjuntos/tommasino_y_cano_ udual_universidades.pdf

Tünnermann, C. (1998). La reforma universitaria de Córdoba. Revista Educación Superior y Sociedad, 9 (1),103-127. Recuperado de http:// extension.fcien.edu.uy/wp-content/uploads/2013/02/Ra\%C3\%ADcessociales-e-ideol $\% \mathrm{C} 3 \% \mathrm{~B} 3$ gicas-de-la-Reforma-de-C $\% \mathrm{C} 3 \% \mathrm{~B} 3$ rdoba.pdf

Villanueva, E. (2011). Acreditación universitaria: Confianza y legitimidad. Revista Iberoamericana de Educación, 57, 53-70. doi: https://doi. org/10.35362/rie570486 